\title{
Economic Analysis of Advanced Fuel Fusion Reactors and Derivation of Scaling Law for COE*)
}

\author{
Takuya KONDO, Kozo YAMAZAKI, Hideki ARIMOTO, Tatsuo SHOJI and Tetsutarou OISHI ${ }^{1)}$ \\ Department of Energy Engineering and Science, Nagoya University, Furo-cho, Chikusa-ku, Nagoya 464-8603, Japan \\ 1) National Institute for Fusion Science, 322-6 Oroshi-cho, Toki 509-5292, Japan
}

(Received 7 December 2012 / Accepted 26 June 2013)

\begin{abstract}
Social acceptance of fusion reactors depends largely on their economic viability. To investigate this issue, we estimate and compare the cost of electricity (COE) among D-T, D- ${ }^{3} \mathrm{He}$, and D-D fusion reactors. Three types of confinement systems are evaluated: the tokamak reactor (TR), the spherical tokamak reactor (STR), and helical reactor (HR). For each reactor type, COE parameter surveys are performed and new scaling laws for COE are derived. The COE for $\mathrm{D}^{3} \mathrm{He}$ and $\mathrm{D}-\mathrm{D}$ is high and depends more strongly on plasma beta value and maximum magnetic field strength than that of D-T.
\end{abstract}

(C) 2013 The Japan Society of Plasma Science and Nuclear Fusion Research

Keywords: cost of electricity, economic, D- ${ }^{3} \mathrm{He}$, D-D, tokamak reactor, spherical tokamak, scaling law, helical reactor

DOI: $10.1585 /$ pfr.8.2405136

\section{Introduction}

Research and development of fusion reactors has primarily focused on the D-T reaction. However, the $14 \mathrm{MeV}$ neutrons produced by this reaction present engineering and safety problems. Therefore, an ultimate future target is to realize an advanced fuel fusion reactor based on the $\mathrm{D}-{ }^{3} \mathrm{He}$ or D-D reaction.

Commercial fusion reactors must not only resolve the technical problems but be socially accepted as well. The latter is largely dependent on reactor fusion economics. In previous studies, we have investigated the economics of D-T, D- ${ }^{3} \mathrm{He}$ and D-D fuel fusion reactors in Tokamak and spherical Tokamak confinement systems [1]. In the present study, we newly evaluate the economics of helical reactors, and perform an extensive parameter survey that clarifies the factors predominantly affecting the economics of advanced fuel fusion reactors.

The economics of D-T fusion reactors has been found to follow a scaling law $[2,3]$. In this paper, we derive new scaling laws for the economics of D-T, D- ${ }^{3} \mathrm{He}$ and D-D fusion reactors.

\section{Analysis Procedures}

The cost of electricity (COE) for fusion reactors is calculated from the physics-engineering-cost (PEC) system code (Fig. 1) [4]. The radial build of fusion-island (FI) components such as blanket and shield is mainly determined from the major radius of the plasma $R_{\mathrm{p}}$ and the component thickness. The volume and weight of each FI component is calculated from the radial build, and is mul-

author'se-mail: yamazaki@ees.nagoya-u.ac.jp

*) This article is based on the presentation at the 22nd International Toki Conference (ITC22).

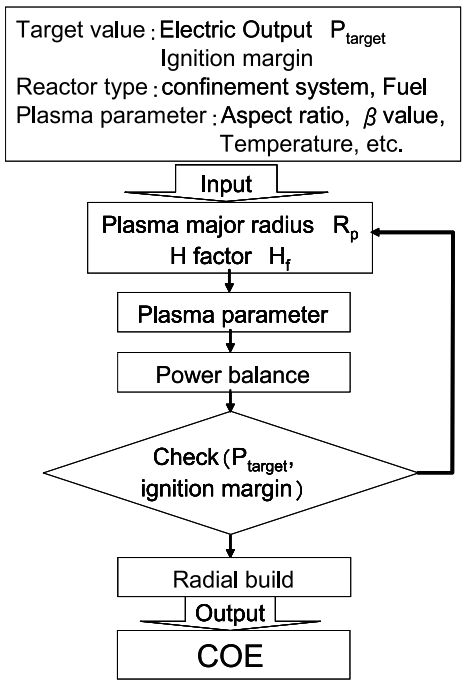

Fig. 1 Flowchart of the PEC code.

tiplied by its unit cost to obtain the cost of the component. The cost of balance of plant (BOP), such as the turbine and the main heat transport system, is estimated from scaling formulas of net electrical and thermal outputs.

\section{Reactor Model}

We considered three types of confinement system and three types of fuel cycles (a total of nine reactor types), whose input and calculated parameters are listed in Table 1. The following input parameters were fixed: target net electric power of $1000 \mathrm{MW}$, plant availability of $75 \%$, operating period 30 years, and target ignition margin of 1.01. Here, the ignition margin is refined by the ratio of the heating power of charged particles (produced by the 
Table 1 Main input and calculated parameters for reference reactor types.

\begin{tabular}{|c|c|c|c|c|c|c|c|c|c|}
\hline \multirow{3}{*}{$\begin{array}{l}\text { Confinement system } \\
\text { Fuel cycle }\end{array}$} & \multirow{2}{*}{\multicolumn{3}{|c|}{$\mathrm{TR}$}} & \multirow{2}{*}{\multicolumn{3}{|c|}{ STR }} & \multirow{2}{*}{\multicolumn{3}{|c|}{$\mathrm{HR}$}} \\
\hline & & & & & & & & & \\
\hline & $\mathrm{D}-\mathrm{T}$ & $\mathrm{D}-{ }^{3} \mathrm{He}$ & D-D & $\mathrm{D}-\mathrm{T}$ & $\mathrm{D}-{ }^{3} \mathrm{He}$ & D-D & $\mathrm{D}-\mathrm{T}$ & $\mathrm{D}-{ }^{3} \mathrm{He}$ & D-D \\
\hline Net electric power $P_{\text {enet }}(\mathrm{GW})$ & 1 & 1 & 1 & 1 & 1 & 1 & 1 & 1 & 1 \\
\hline Normalized beta $\beta_{\mathrm{N}}^{\mathrm{a}}$ & 4 & 8 & 8 & 8 & 8 & 8 & $(7)$ & $(16)$ & $(16)$ \\
\hline Average beta value $\langle\beta\rangle(\%)$ & 5.27 & 10.55 & 10.55 & 30.19 & 30.19 & 30.19 & 5.00 & 12.00 & 12.00 \\
\hline Aspect ratio $A^{\mathrm{a}}$ & 3.54 & 3.54 & 3.54 & 1.62 & 1.62 & 1.62 & 7.81 & 7.81 & 7.81 \\
\hline Ellipticity $\kappa^{\mathrm{a}}$ & 2.00 & 2.00 & 2.00 & 3.50 & 3.50 & 3.50 & 2.00 & 2.00 & 2.00 \\
\hline Maximum field $B_{\max }(\mathrm{T})^{\mathrm{a}}$ & 13 & 13 & 13 & 8.75 & 13 & 13 & 13 & 13 & 13 \\
\hline Central ion temperature $T_{\mathrm{i}}(0)(\mathrm{KeV})^{\mathrm{a}}$ & 30 & 70 & 70 & 30 & 70 & 70 & 20 & 70 & 70 \\
\hline Maximum coil current density $J_{\max }\left(\mathrm{MA} / \mathrm{m}^{2}\right)^{\mathrm{a}}$ & 30 & 30 & 30 & 13 & 30 & 30 & 30 & 30 & 30 \\
\hline Plasma major radius $R_{\mathrm{p}}(\mathrm{m})$ & 6.33 & 11.52 & 10.90 & 3.98 & 8.23 & 7.94 & 14.31 & 16.03 & 17.62 \\
\hline Toroidal field $B_{\mathrm{t}}(\mathrm{T})$ & 6.13 & 8.08 & 8.07 & 2.34 & 3.62 & 3.57 & 4.35 & 8.05 & 7.31 \\
\hline Fusion power (GW) & 3.35 & 3.09 & 2.79 & 4.56 & 2.96 & 2.69 & 2.36 & 2.40 & 2.32 \\
\hline Neutron power (GW) & 2.68 & 0.07 & 0.55 & 3.65 & 0.07 & 0.53 & 1.88 & 0.06 & 0.46 \\
\hline Ohmic loss (GW) & & & & 0.96 & & & & & \\
\hline Power density $\left(\mathrm{MW} / \mathrm{m}^{3}\right)$ & 4.61 & 0.71 & 0.75 & 3.18 & 0.23 & 0.24 & 1.24 & 0.90 & 0.65 \\
\hline Plasma current (MA) & 14.49 & 34.72 & 32.81 & 21.64 & 69.40 & 66.00 & 0.00 & 0.00 & 0.00 \\
\hline Current drive power (MW) & 138.82 & 87.86 & 78.32 & 10.55 & 72.01 & 64.21 & 0.00 & 0.00 & 0.00 \\
\hline HH factor $\quad\left(H_{\mathrm{ITER}}, H_{\mathrm{ISS}}\right)$ & 1.21 & 3.27 & 4.13 & 1.74 & 2.97 & 3.41 & 4.63 & 18.94 & 21.04 \\
\hline Density limit $\bar{n} / n_{\mathrm{GW}}$ & 1.12 & 2.31 & 2.18 & 1.17 & 1.61 & 1.53 & $(2.05)$ & $(2.93)$ & $(2.94)$ \\
\hline Density limit $\bar{n} / n_{\mathrm{LHD}}$ & $(0.66)$ & $(0.97)$ & $(1.04)$ & $(1.08)$ & (1.49) & $(1.60)$ & 0.88 & 0.80 & 0.89 \\
\hline $\mathrm{COE}($ cent $/ \mathrm{kWh})$ & 10.89 & 13.09 & 13.33 & 10.26 & 14.40 & 14.69 & 11.55 & 17.12 & 20.10 \\
\hline Neutron wall load $\left(\mathrm{MW} / \mathrm{m}^{2}\right)$ & 3.54 & 0.03 & 0.25 & 4.99 & 0.02 & 0.18 & 1.08 & 0.03 & 0.17 \\
\hline
\end{tabular}

fusion reaction) to the loss power (including power lost by radiation).

\subsection{Confinement systems}

The confinement systems adopted here are the tokamak reactor (TR), spherical tokamak reactor (STR) and Helical Reactor (HR). The aspect ratio $(A)$ and normalized beta value $\left(\beta_{\mathrm{N}}\right)$ of the TR reactor were set as 3.54 and 4 (D$\mathrm{T})$, respectively. $\mathrm{D}-{ }^{3} \mathrm{He}$ and $\mathrm{D}-\mathrm{D}\left(\beta_{\mathrm{N}}=8\right)$ are assigned a high $\beta_{\mathrm{N}}$. In the STR, we can omit the inner blanket and use a normal conducting coil system for the center post coil, permitting a low aspect ratio $(A=1.62)$. Because a high beta value is expected in the ST, we again assume $\beta_{\mathrm{N}}=8$. However, the use of a normal conducting coil (maximum field strength $B_{\max }=8.75$ ) requires that some of the electricity output by the STR compensates for power lost by ohmic heating in the coil system. In the TR and STR, the current drive power $P_{\mathrm{CD}}$ depends on the average electron density $\langle n\rangle, R_{\mathrm{P}}$, the plasma current $I_{\mathrm{P}}$, and the bootstrap current $I_{\mathrm{BS}}$; more specifically, $P_{\mathrm{CD}}=2.0\langle n\rangle R_{\mathrm{P}}\left(I_{\mathrm{P}}-I_{\mathrm{BS}}\right)$. Since the HR confinement system does not use plasma current, this system requires no external current drive power. The reference blanket model of TR and STR is $\mathrm{Li}_{2} \mathrm{O} / \mathrm{FS}$, as in the Steady-State Tokamak reactor (SSTR) [5], while that of HR is Flibe/FS, as in the Force-Free Helical Reactor (FFHR) [6]. The electron and ion temperatures are assumed equal. Plasma density and temperature radial profiles are assumed parabolic: $n(r)=n_{0}\left(1-r^{2}\right)^{0.25}$ and $T(r)=T_{0}\left(1-r^{2}\right)^{1}$, where $T_{0}$ and $n_{0}$ are the central temperature and density, respectively, and $r$ is the normalized small radius.

\subsection{Fuel cycle}

We evaluated three types of fuel cycles: D-T, D- ${ }^{3} \mathrm{He}$ and D-D. Since D- ${ }^{3} \mathrm{He}$ reactors generate very few neutrons and do not breed tritium, these reactors are not supplied with a breeding blanket. The shield thickness of a D- ${ }^{3} \mathrm{He}$ TR is assumed as $0.7 \mathrm{~m}$, as in ARIES-3 [7]. Since ${ }^{3} \mathrm{He}$ gas is a very rare terrestrial resource, we assumed a scenario in which ${ }^{3} \mathrm{He}$ is transported from the lunar surface and estimated its cost as $200 \mathrm{US} \$ / \mathrm{g}$ [8]. The D-D reactor system recycles $\mathrm{T}$ and ${ }^{3} \mathrm{He}$ produced by the $\mathrm{D}-\mathrm{D}$ reaction and extracts energy from $\mathrm{D}-\mathrm{T}$ and $\mathrm{D}-{ }^{3} \mathrm{He}$ reactions (catalyzed D-D). The respective inboard and outboard blanket thicknesses of D-D TR are 0.21 and $0.41 \mathrm{~m}$, whereas the inboard and outboard shield thicknesses are 0.44 and $1.00 \mathrm{~m}$, as seen in WILDcat [9]. In STR, because of low neutron wall load for the $\mathrm{D}-{ }^{3} \mathrm{He}$ and catalyzed $\mathrm{D}-\mathrm{D}$ reactors, we set the inboard shield thickness as $0.56 \mathrm{~m}$ for both D- ${ }^{3} \mathrm{He}[10]$ and D-D, and suppose that STR uses a superconducting coil $\left(B_{\max }=13 \mathrm{~T}\right)$. The ratio of ion to electron density $\left(n_{\mathrm{i}} / n_{\mathrm{e}}\right)$ is assumed as $1.00(\mathrm{D}-\mathrm{T}), 0.66,\left(\mathrm{D}-{ }^{3} \mathrm{He}\right)$, 0.90 (D-D).

\section{Assessment Results \\ 4.1 Parameter dependence}

For each type of reactor, we calculated the dependence of COE on beta value $(\beta)$, maximum magnetic field $\left(B_{\max }\right)$, net electric power $\left(P_{\text {enet }}\right)$, and thermal efficiency $\left(f_{\text {th }}\right)$, using the parameters from Table 1 . The results for TR, STR, and HR are shown in Figs. 2, 3, and 4, respectively. Since higher $\beta$ and $B_{\max }$ characterize higher plasma density, they are also associated with higher power density. Consequently, the plasma volume that satisfies $P_{\text {enet }}$ is re- 

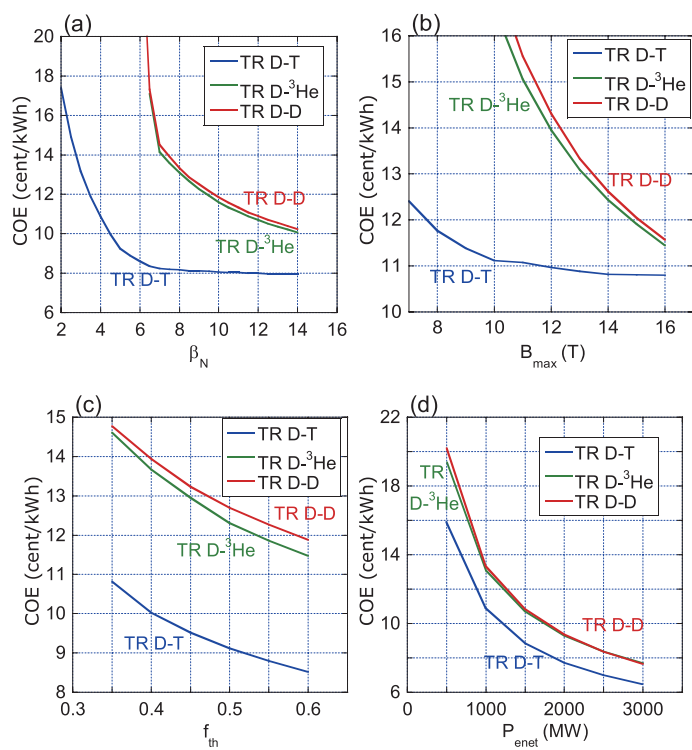

Fig. 2 Dependence of COE on (a) $\beta_{\mathrm{N}}$, (b) $B_{\max }$, (c) $f_{\text {th }}$ and (d) $P_{\text {enet }}$ of TR.
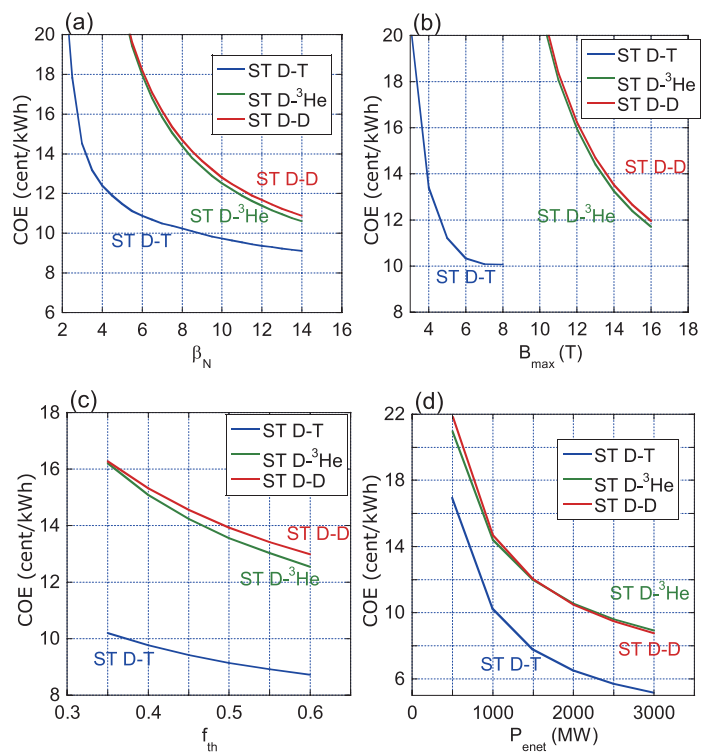

Fig. 3 Dependence of COE on (a) $\beta_{\mathrm{N}}$, (b) $B_{\max }$, (c) $f_{\text {th }}$ and (d) $P_{\text {enet }}$ of STR.

duced and a smaller reactor is required, reducing both the construction cost and COE. Since the reaction rate of an advanced fuel fusion reactor is very low, the COE for such a reactor is higher than that of $\mathrm{D}-\mathrm{T}$.

In TR, the bootstrap current ratio is assumed to be a function of poloidal beta value. At $\beta_{\mathrm{N}}<7$, the bootstrap current ratio is $<95 \%$. Because a low bootstrap current ratio requires high current drive power, the power of the circulating electricity increases, along with the required fusion power. As a result, the $\mathrm{COE}$ in advanced fuel reactors is also increased by low bootstrap current ratio.

Since the STR D-T reactor uses a normal conducting coil system, we assume a small value of $B_{\max }$ in this reac-
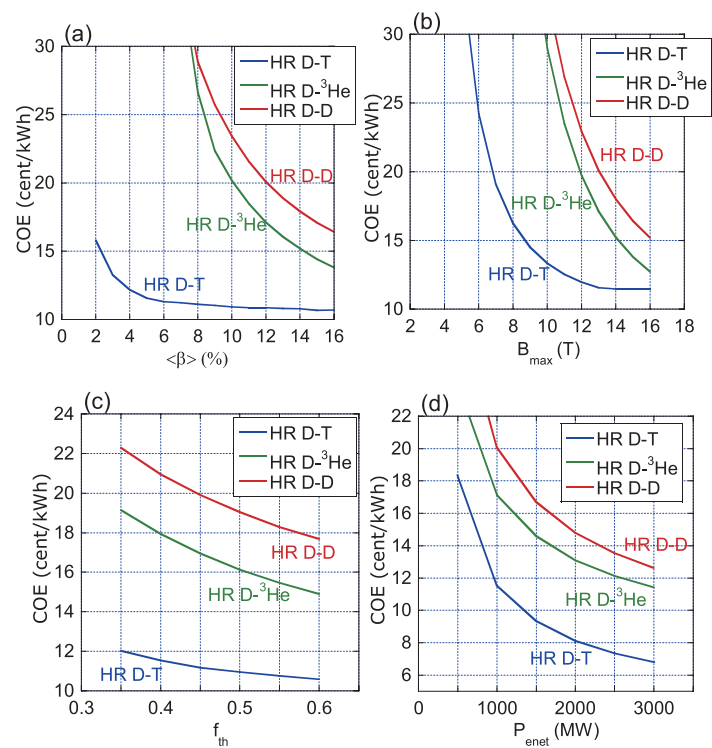

Fig. 4 Dependence of COE on (a) $\langle\beta\rangle$, (b) $B_{\max }$, (c) $f_{\text {th }}$ and (d) $P_{\text {enet }}$ of HR.

Table 2 Design parameters for scaling laws.

\begin{tabular}{llcc}
\hline & & $\beta_{\mathrm{N}},\langle\beta\rangle(\%)$ & $B_{\max }(\mathrm{T})$ \\
\hline \multirow{2}{*}{ TR } & D-T & $2-5$ & $10-16$ \\
& D- ${ }^{3} \mathrm{He}, \mathrm{D}-\mathrm{D}$ & $6-14$ & $10-16$ \\
\hline \multirow{2}{*}{ STR } & D-T & $6-12$ & $4-10$ \\
& ${ }^{3}{ }^{3} \mathrm{He}, \mathrm{D}-\mathrm{D}$ & $6-14$ & $10-16$ \\
\hline \multirow{2}{*}{$\mathrm{HR}$} & D-T & $2-6$ & $10-16$ \\
& $\mathrm{D}^{3} \mathrm{He}, \mathrm{D}-\mathrm{D}$ & $6-14$ & $10-16$ \\
\hline
\end{tabular}

tor. Moreover, the power of the circulating electricity must be increased to compensate for ohmic heating loss in the coil.

In the advanced fuel reactor of $\mathrm{HR}$, the COE strongly depends on beta value and magnetic field strength, and the ISS confinement scaling law specifies an extremely high $\mathrm{H}$ factor. Thus, the confinement requires much improvement in the high temperature regime of HR.

In all reactors types, the $\mathrm{COE}$ is reduced by high $f_{\text {th }}$ and $P_{\text {enet }}$. In particular, high-powered reactors incur small COE.

\subsection{COE scaling laws}

In addition to the survey parameters, the design parameters were the plant availability $\left(f_{\text {avail }}\right)$ and operating period $\left(t_{\text {oper }}\right)$. The COE scaling laws were derived from multiple regression analysis. The ranges of $\beta$ and $B_{\max }$ are listed in Table 2; $P_{\text {enet }}$ covers $0.5-3.0 \mathrm{GW}, f_{\text {avail }}$ is 0.65 $0.8, t_{\text {oper }}$ is $20-40$ year and $f_{\text {th }}$ is $0.35-0.60$. The new scaling laws are derived as follows.

$$
\begin{aligned}
C O E^{\mathrm{TRD}-\mathrm{T}}[\mathrm{cent} / \mathrm{kWh}] & 1 \\
& =10^{2.36} \frac{1}{\beta_{\mathrm{N}}^{0.54} B_{\text {max }}^{0.11} P_{\text {enet }}^{0.53} f_{\text {avail }}^{0.91} t_{\text {oper }}^{0.79} f_{\text {th }}^{0.48}},
\end{aligned}
$$




$$
\begin{aligned}
& C O E^{\mathrm{TRD}-{ }^{3} \mathrm{He}}[\text { cent } / \mathrm{kWh}] \\
& =10^{3.49} \frac{1}{\beta_{\mathrm{N}}^{0.83} B_{\text {max }}^{0.52} P_{\text {enrt }}^{0.56} f_{\text {avail }}^{0.92} t_{\text {oper }}^{0.82} f_{\text {th }}^{0.39}}, \\
& C O E^{\mathrm{TRD}-\mathrm{D}}[\text { cent } / \mathrm{kWh}] \\
& =10^{3.67} \frac{1}{\beta_{\mathrm{N}}^{0.86} B_{\text {max }}^{0.60} P_{\text {enet }}^{0.58} f_{\text {avail }}^{0.95} t_{\text {oper }}^{0.85} f_{\text {th }}^{0.37}}, \\
& C O E^{\mathrm{STD}-\mathrm{T}}[\text { cent } / \mathrm{kWh}] \\
& =10^{2.53} \frac{1}{\beta_{\mathrm{N}}^{0.33} B_{\text {max }}^{0.30} P_{\text {enet }}^{0.62} f_{\text {avail }}^{0.95} t_{\text {oper }}^{0.82} f_{\text {th }}^{0.33}}, \\
& C O E^{\mathrm{STD}-{ }^{3} \mathrm{He}}[\text { cent } / \mathrm{kWh}] \\
& =10^{4.05} \frac{1}{\beta_{\mathrm{N}}^{0.67} B_{\text {max }}^{1.14} P_{\text {enet }}^{0.48} f_{\text {avail }}^{0.94} t_{\text {oper }}^{0.85} f_{\text {th }}^{0.48}}, \\
& C O E^{\mathrm{STD}-\mathrm{D}}[\text { cent } / \mathrm{kWh}] \\
& =10^{4.01} \frac{1}{\beta_{\mathrm{N}}^{0.62} B_{\text {max }}^{1.09} P_{\text {enet }}^{0.55} f_{\text {avail }}^{0.96} t_{\text {oper }}^{0.87} f_{\text {th }}^{0.40}}, \\
& C O E^{\mathrm{HRD}-\mathrm{T}}[\text { cent } / \mathrm{kWh}] \\
& =10^{2.97} \frac{1}{\langle\beta\rangle^{0.33} B_{\text {max }}^{0.60} P_{\text {enet }}^{0.54} f_{\text {avail }}^{0.92} t_{\text {oper }}^{0.84} f_{\text {th }}^{0.34}}, \\
& C O E^{\mathrm{HRD}-{ }^{3} \mathrm{He}}[\text { cent } / \mathrm{kWh}] \\
& =10^{6.13} \frac{1}{\langle\beta\rangle^{1.35} B_{\max }^{2.11} P_{\text {enet }}^{0.46} f_{\text {avail }}^{0.96} t_{\text {oper }}^{0.91} f_{\text {th }}^{0.52}}, \\
& C O E^{\mathrm{HRD}-\mathrm{D}}[\text { cent } / \mathrm{kwh}] \\
& =10^{5.85} \frac{1}{\langle\beta\rangle^{1.16} B_{\max }^{1.98} P_{\text {enet }}^{0.46} f_{\text {avail }}^{0.96} t_{\text {oper }}^{0.92} f_{\text {th }}^{0.50}} .
\end{aligned}
$$

In $\mathrm{D}^{3} \mathrm{He}$ and D-D, the $\beta$ and $B_{\max }$ exponents exceed those of D-T, and the COE of these advanced fusion reactors strongly depends on $\beta$ and $B_{\max }$.

\section{Summary}

We have calculated the COE of advanced fuel fusion reactors in three types of confinement systems and derived new scaling laws for the COE of advanced fuel reactors.

Since the reaction rate in advanced fuel fusion reactors is very low, more plasma volume is required than in the $\mathrm{D}-\mathrm{T}$ reactor to produce the same target net electric power. Therefore the plant construction cost, and consequently the $\mathrm{COE}$, is increased. To achieve COE similar to that of the D-T Tokamak reactor TR $\left(\beta_{\mathrm{N}}=4\right)$, the $\beta_{\mathrm{N}}$ should be raised in the D- ${ }^{3} \mathrm{He}$ and D-D TR reactors $\left(\beta_{\mathrm{N}}>10\right)$. However, high $\beta_{\mathrm{N}}(>5)$ is not readily attained in a conventional TR. If high $\beta_{\mathrm{N}}$ could be realized in spherical tokamak confinement systems, together with high magnetic field generated by the superconducting coil, the COE of $\mathrm{D}-{ }^{3} \mathrm{He}$ would become comparable to that of D-T.

[1] T. Kondo, K. Yamazaki et al., Plasma Fusion Res. 7, 2405067 (2012).

[2] D. Maisonnier, I. Cook et al., Fusion Eng. Des. 75-79, 1178 (2005).

[3] K. Mori, K. Yamazaki et al., Plasma Fusion Res. 6, 2405126 (2011).

[4] K.Yamazaki and T.J. Dolan, Fusion Eng. Des. 81, 1145 (2006).

[5] S. Nishio, T. Ando, Y. Ohara et al., Fusion Eng. Des. 18, 249 (1991)

[6] A. Sagara, O. Motojima et al., Fusion Eng. Des. 29, 51 (1995).

[7] F. Najmabadi, R.W. Conn et al., "The ARIES-III Tokamak Fusion Reactor Study-The final report," UCLA report UCLA-PPG-1384, (1992).

[8] L.J. Wittenberg, E.N. Cameron et al., Fusion Technol. 21, 2230 (1991).

[9] K. Evans, Jr. et al., WILDCAT: a catalyzed D-D tokamak reactor, ANL/FPP/TM-150 (1980).

[10] H. Shimotohno, S. Nishio and S. Kondo, Fusion Eng. Des. 69, 675 (2003) 